\title{
Effect of Sn Addition on Evolution of Primary Recrystallization Texture in 3\% Si Steel
}

\author{
Ryuichi SUEHIRO, ${ }^{*}$ Yasuyuki HAYAKAWA and Toshito TAKAMIYA \\ Steel Research Laboratory, JFE Steel Corporation, 1-Kawasakidori, Mizushima, Kurashiki, 712-8511 Japan. \\ (Received on March 28, 2018; accepted on September 26, 2018)
}

\begin{abstract}
The evolution of the primary recrystallization texture was investigated for 3\%Si steel without and with solute Sn. The texture component just after the completion of recrystallization was $\{111\}<112>$ in both the Sn-less steel and the Sn-added steel. However, while the $\{111\}<112>$ orientation remained the main texture component in the Sn-less steel after grain growth at $850^{\circ} \mathrm{C}$, the $\{411\}<148>$ orientation replaced the $\{111\}<112>$ orientation as the main texture component in the Sn-added steel. In Sn less steel, the frequency of low angle boundaries decreased during grain growth indicating the movement of low angle boundaries which are major boundaries around $\{111\}<112>$ grains. The addition of Sn selectively suppressed the decrease of the frequency of low angle during grain growth. The Monte-Carlo grain growth simulation in which the mobility of grain boundaries depended on the grain boundary misorientation angle $(\omega)$ was conducted. The simulation results suggested that reducing mobility of low angle boundaries $\left(\omega<15^{\circ}\right)$ and high angle boundaries $\left(\omega>45^{\circ}\right)$ enhanced the development of $\{411\}<148>$ grains during grain growth with high angle boundaries $\left(15<\omega<45^{\circ}\right)$, which are major boundaries around $\{411\}<148>$ grains. The difference in mobility between the low angle boundaries $\left(\omega<15^{\circ}\right)$ and high angle boundaries $\left(15<\omega<45^{\circ}\right)$ is caused by anisotropic solute drag effect on the grain boundaries and would result in the preferential texture evolution observed in the Sn-added steel.
\end{abstract}

KEY WORDS: electrical steel; recrystallization; texture; grain growth; grain boundary; segregation; simulation.

\section{Introduction}

Non-oriented electrical steels have been widely used as core materials of motors. The role of these materials is to induce high magnetic flux and to pass the magnetic flux along the magnetic circuit. To satisfy these roles, high permeability and low core loss are required in non-oriented electrical steels. One method for achieving the required magnetic properties is to control the recrystallization texture of the steel. For example, reducing the $\{111\}$ component in recrystallization texture is known as an effective way to reduce core loss. ${ }^{1)}$

It is well known that the recrystallization texture can be controlled by adding certain microelements. Hao et $a l^{2)}$ reported that the addition of Sn to non-oriented electrical steel suppressed the development of the $\{111\}$ component and reduced core loss. Kubota et al. ${ }^{3)}$ also reported the coincident increase of the $\{411\},\{110\},\{100\}$ components and the decrease of the $\{111\}$ component by the addition of Sn with cold rolling reduction rates higher than $80 \%$. Kubota et $a l .{ }^{3)}$ reported that $\mathrm{Sn}$ increased the formation of deformation bands during cold rolling. Since $\{110\}$ grains preferentially nucleate at deformation bands, the $\{110\}$ components in the recrystallization texture increase and the $\{111\}$ components

* Corresponding author: E-mail: r-suehiro@jfe-steel.co.jp

DOI: https://doi.org/10.2355/isijinternational.ISIJINT-2018-223 which nucleate near grain boundaries decrease by Sn addition. Nakajima et al. $^{4)}$ suggested that the addition of $\mathrm{Sn}$ enhanced the formation of fine carbides during hot-band annealing, which promoted the formation of deformation bands. It has also been confirmed that the addition of $\mathrm{Sn}$ resulted in grain boundary segregation of $\mathrm{Sn}^{2,4,5}$ and retardation of the onset of recrystallization ${ }^{4)}$ during primary recrystallization. Hao et $a l^{2)}$ suggested that the reduction of the grain boundary energy caused by the grain boundary segregation of Sn affected the nucleation and grain growth of $\{111\}$ grains. Godec et al. ${ }^{5)}$ suggested that the surface segregation of Sn selectively decreased the surface energy of grains and selectively increased the mobility of some grain boundaries.

The effect of the addition of segregation atoms other than $\mathrm{Sn}$, for example, $\mathrm{Sb}^{6-9)}$ and $\mathrm{P}^{10-14)}$ on the recrystallization texture has also been discussed. Tanaka et al. ${ }^{14)}$ suggested that $\Sigma 9$ coincidence site lattice (CSL) boundaries had priority in grain boundary migration under the solute drag effect of $\mathrm{P}$, and this effect resulted in selective grain growth of the $\left\{\varphi_{1}, \Phi, \varphi_{2}\right\}=\left\{25^{\circ}, 10-15^{\circ}, 45^{\circ}\right\}$ component; $\varphi_{1}, \Phi$, $\varphi_{2}$ are Bunge Euler angles representing crystal orientation. However, the behavior of grain boundary migration during grain growth under the existence of segregation atoms is still unclear. Therefore, in this study, the effect of Sn addition on texture evolution, especially during grain growth, was investigated. 


\section{Experimental}

Two vacuum-melted steel ingots were prepared in this study. The chemical compositions of the steels are shown in Table 1. The amount of $\mathrm{Sn}$ in $0.0 \mathrm{Sn}$ and $0.1 \mathrm{Sn}$ was $<0.001$ and 0.10 mass $\%$, respectively. The ingots were hot-rolled to $2.2 \mathrm{~mm}$ thickness after soaking at $1200^{\circ} \mathrm{C}$ for $20 \mathrm{~min}$. The hot bands were then annealed at $850^{\circ} \mathrm{C}$ for $40 \mathrm{~s}$ in a nitrogen atmosphere and subjected to cold rolling with a reduction of $88 \%$. The finishing thickness was $0.27 \mathrm{~mm}$. Some of the cold-rolled sheets were heated to $650-850^{\circ} \mathrm{C}$ in a nitrogen atmosphere and cooled to room temperature by nitrogen gas cooling. Remained cold-rolled sheets were annealed at $850^{\circ} \mathrm{C}$ for 0,30 or $120 \mathrm{~s}$ in a nitrogen atmosphere for primary recrystallization and grain growth. All of the annealing after cold rolling was performed using direct current heating furnace at a heating rate of $20^{\circ} \mathrm{C} / \mathrm{s}$.

The optical microstructures of the sheets heated to $650-850^{\circ} \mathrm{C}$ after cold rolling were investigated by optical microscopy. Texture characterization was carried out by X-ray pole figure measurements. On the center layer of annealed sheets of samples which were chemically polished, the incomplete $\{100\},\{110\},\{211\}$ and $\{111\}$ pole figures were measured. Orientation distribution functions (ODFs) were calculated from these figures using the method proposed by Pawlik. ${ }^{15)}$ Sn segregation behavior after the primary recrystallization was characterized by Auger electron spectroscopy (AES) analysis. Samples annealed with same condition were cut into $18.1 \times 3.0 \mathrm{~mm}$ and stacked in $2 \mathrm{~mm}$ thickness. The stacked samples were notched at center of length and maintained in liquid nitrogen in the AES chamber for 2 hour and fractured by impact. AES measurements were conducted using PHI SAM650. Typical parameters for the AES measurement were as follows: vacuum $=1 \times 10^{-10}$ Torr, acceleration voltage $=5 \mathrm{kV}$, emission current $=0.2 \mu \mathrm{A}$.

\section{Results}

Figure 1 shows the optical microstructures of the $0.0 \mathrm{Sn}$ steel heated to $650-850^{\circ} \mathrm{C}$. At $650^{\circ} \mathrm{C}$, most of the initial microstructure remained. At $750^{\circ} \mathrm{C}$, recrystallization progressed but a small portion of the rolling structure remained. The completion of recrystallization was confirmed at $800^{\circ} \mathrm{C}$. Grain growth was observed after the completion of recrystallization. Figure 2 shows the optical microstructures of the $0.1 \mathrm{Sn}$ steel heated to $650-850^{\circ} \mathrm{C}$. The progress of recrystallization was slower than in $0.0 \mathrm{Sn}$. The rolling structure remained in the texture of the $0.1 \mathrm{Sn}$ steel at $800^{\circ} \mathrm{C}$. The completion of recrystallization of $0.1 \mathrm{Sn}$ was confirmed at $850^{\circ} \mathrm{C}$. Furthermore, the grain size of the $0.1 \mathrm{Sn}$ steel after grain growth annealing was smaller than that of $0.0 \mathrm{Sn}$ steel.

Figure 3 shows the average grain diameter of the sheets after grain growth annealing. The grain diameter just after

Table 1. Chemical compositions of steels.

\begin{tabular}{ccccc}
\hline Steel & \multicolumn{1}{c}{} & & $($ mass\%) \\
\hline $0.0 \mathrm{Sn}$ & 0.0018 & 3.12 & 0.06 & $\mathrm{Sn}$ \\
\hline $0.1 \mathrm{Sn}$ & 0.0028 & 3.18 & 0.06 & 0.10 \\
\hline
\end{tabular}

the completion of recrystallization of the $0.0 \mathrm{Sn}$ steel was $20.4 \mu \mathrm{m}$ and that of $0.1 \mathrm{Sn}$ was $20.2 \mu \mathrm{m}$. After grain growth annealing at $850^{\circ} \mathrm{C}$ for $120 \mathrm{~s}$, the average grain diameters of $0.0 \mathrm{Sn}$ and $0.1 \mathrm{Sn}$ were $93 \mu \mathrm{m}$ and $80.2 \mu \mathrm{m}$, respectively. Figure 4 shows the scanning electron microscopy images (a)

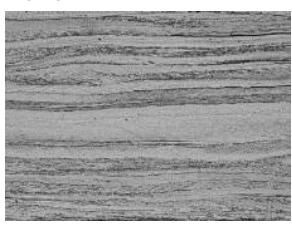

(c)

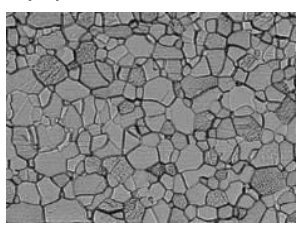

(e)

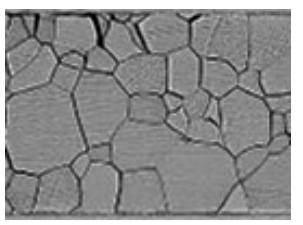

ND (b)

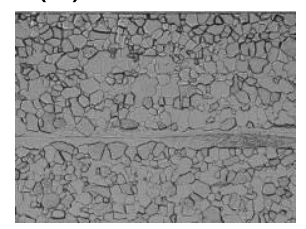

(d)

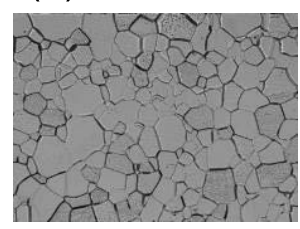

(f)
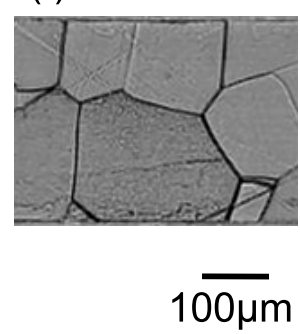

Fig. 1. Optical microstructures of the $0.0 \mathrm{Sn}$ steel heated to (a) $650^{\circ} \mathrm{C}$, (b) $750^{\circ} \mathrm{C}$, (c) $800^{\circ} \mathrm{C}$, (d) $850^{\circ} \mathrm{C}$ and annealed at $850^{\circ} \mathrm{C}$ for (e) $30 \mathrm{~s}$ and (f) $120 \mathrm{~s}$ after cold rolling. (a)

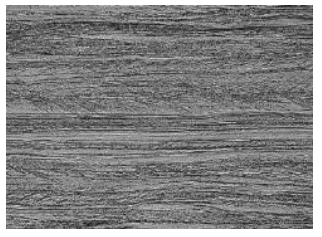

(c)

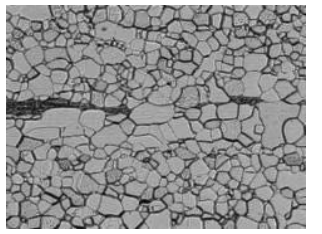

(e)

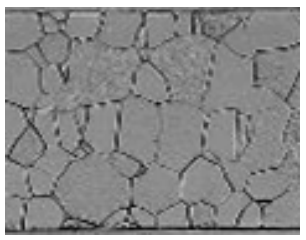

ND

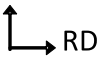

(b)

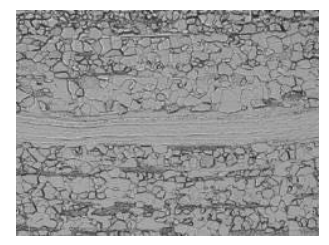

(d)

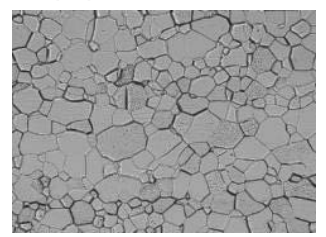

(f)

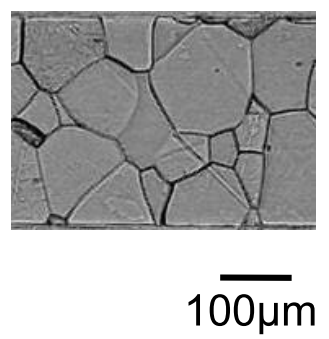

Fig. 2. Optical microstructures of the $0.1 \mathrm{Sn}$ steel heated to (a) $650{ }^{\circ} \mathrm{C}$, (b) $750^{\circ} \mathrm{C}$, (c) $800^{\circ} \mathrm{C}$, (d) $850^{\circ} \mathrm{C}$ and annealed at $850^{\circ} \mathrm{C}$ for (e) $30 \mathrm{~s}$ and (f) $120 \mathrm{~s}$ after cold rolling. 
and Auger spectrum of as-recrystallized $0.1 \mathrm{Sn}$ steel at a transgranular fracture and an intergranular fracture measured by AES. Sn peak was observed only at intergranular

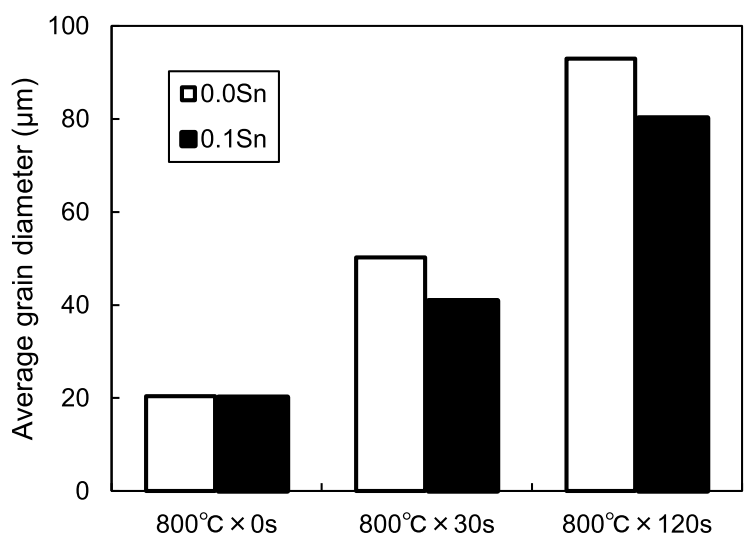

Fig. 3. Average grain diameter after grain growth annealing.

(a)

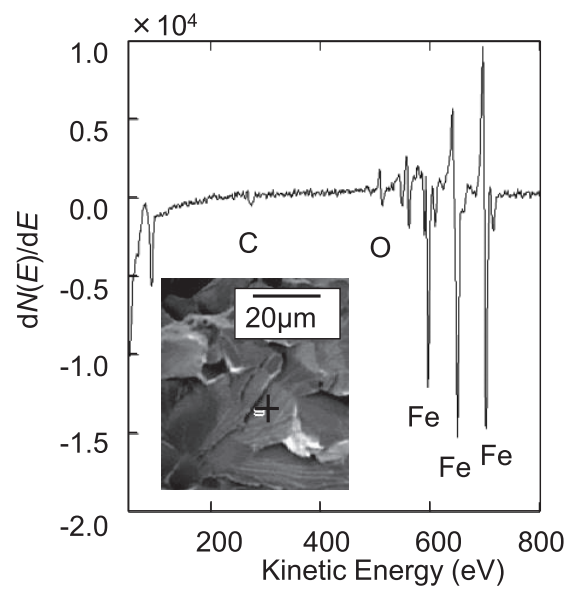

fracture. According to the phase diagram of Fe-Si-Sn system, ${ }^{16)} \mathrm{Sn}$ atoms in the steel with chemical composition of $0.1 \mathrm{mass} \% \mathrm{Sn}$ and 3.18 mass $\% \mathrm{Si}$ are in solid solution. In addition, any precipitation of $\mathrm{Sn}$ composition has not been reported in former studies. ${ }^{3,4)}$ Hence, it was assumed that $\mathrm{Sn}$ atoms were segregated at grain boundaries as solute atoms after the primary recrystallization.

The evolution of the recrystallization texture of the 0.0Sn steel during grain growth annealing is shown in Fig. 5. Just after the completion of recrystallization, the main component of the texture was the $\{111\}<112>$ component. During grain growth annealing, not only the $\{111\}<112>$ component but also components around the $\{111\}<112>$ orientation developed. However, the $\{111\}<112>$ orientation remained the main component of the texture even after annealing at $850^{\circ} \mathrm{C}$ for $120 \mathrm{~s}$. The texture of the $0.1 \mathrm{Sn}$ steel is shown in Fig. 6. Compared with the 0.0Sn steel, the texture of the $0.1 \mathrm{Sn}$ steel just after the completion of

(b)

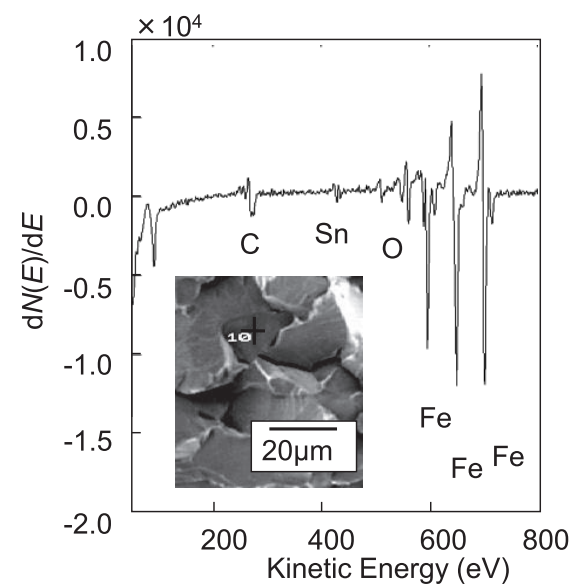

Fig. 4. Auger spectrum of as-recrystallized the 0.1Sn steel at (a) a transgranular fracture and (b) an intergranular fracture. Insets show FEM images of the fractures where the Auger spectra were measured.

(a)

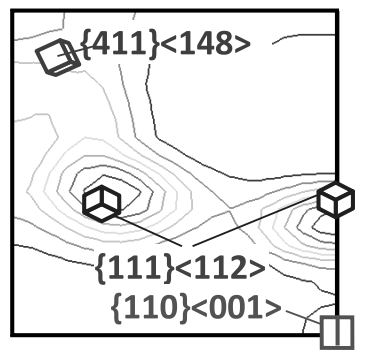

(b)

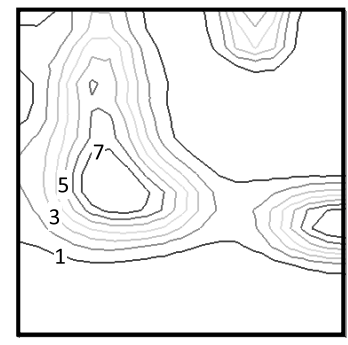

(c)
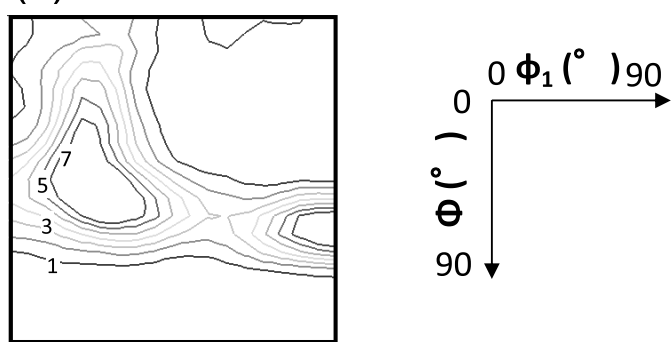

Fig. 5. $\varphi_{2}=45^{\circ}$ sections of ODFs of the $0.0 \mathrm{Sn}$ steel after primary recrystallization annealing at (a) $800^{\circ} \mathrm{C} \times 0 \mathrm{~s}$, (b) $850^{\circ} \mathrm{C} \times$ $30 \mathrm{~s}$ and $(\mathrm{c}) 850^{\circ} \mathrm{C} \times 120 \mathrm{~s}$. (a)

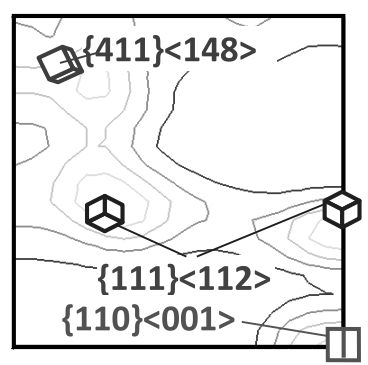

(b)

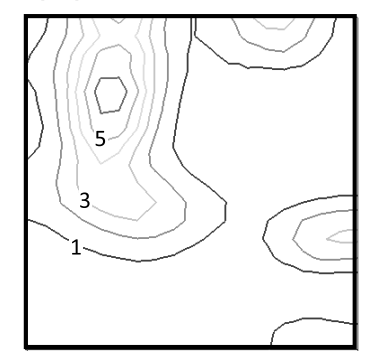

(c)
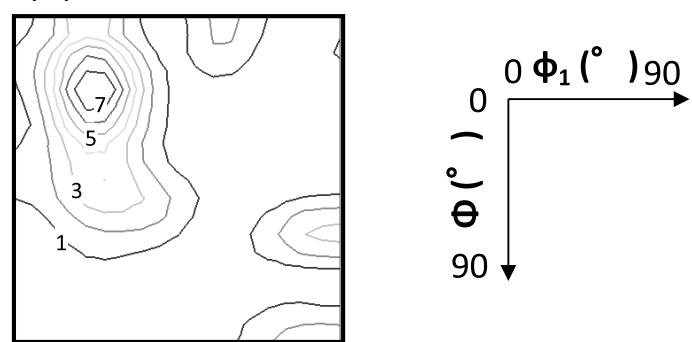

Fig. 6. $\varphi_{2}=45^{\circ}$ sections of ODFs of the $0.1 \mathrm{Sn}$ steel after primary recrystallization annealing at (a) $850^{\circ} \mathrm{C} \times 0 \mathrm{~s}$, (b) $850^{\circ} \mathrm{C} \times$ $30 \mathrm{~s}$ and (c) $850^{\circ} \mathrm{C} \times 120 \mathrm{~s}$. 
primary recrystallization consisted of three components, $\{111\}<112>,\{411\}<148>$ and $\{110\}<001>$ (Goss), and the $\{411\}<148>$ component became the main component after grain growth annealing.

\section{Discussion}

\subsection{Grain Boundary Misorientation Angle Analysis}

Based on the result that the addition of Sn not only retarded grain growth but also changed the texture after grain growth, it is assumed that the segregation of $\mathrm{Sn}$ affected grain growth behavior depending on the characteristics of the migrating grain boundaries.

To investigate the effect of the characteristics of the grain boundaries on grain boundary migration under the coexistence of $\mathrm{Sn}$ segregation, a grain boundary misorientation angle analysis was conducted on the center layer of the samples after primary recrystallization annealing using the electron back scatter diffraction (EBSD) pattern method. The samples were prepared by chemical polishing of the center layer of sheets after primary recrystallization annealing.

Figure 7 shows the grain map of the 0.0Sn steel and the $0.1 \mathrm{Sn}$ steel before and after grain growth measured by EBSD. Goss, $\{111\}<112>$ and $\{411\}<148>$ grains were colored in red, blue and green respectively. In the $0.0 \mathrm{Sn}$ steel, the $\{111\}<112>$ grains remained as the main component after the grain growth. In the $0.1 \mathrm{Sn}$ steel, in contrast, the fraction of $\{111\}<112>$ grains decreased during grain growth and the larger fraction of $\{411\}<148>$ grains remained after the grain growth. These grain growth behaviors were consistent with the texture evolution as shown in
Figs. 5 and 6.

In the grain boundary misorientation angle analysis, the distribution of the grain boundary misorientations around grains with a focused orientation within a $10^{\circ}$ tolerance angle was calculated. For example, Fig. 8 shows the grain map of the $0.0 \mathrm{Sn}$ steel where low angle boundaries $\left(\omega<20^{\circ}\right)$ surrounding $\{111\}<112>$ grains are shown in red, and high angle boundaries $\left(20<\omega<40^{\circ}\right)$ are shown in green.

Figure 9 shows the distribution of misorientation angles around $\{111\}<112>$ grains. In the $0.0 \mathrm{Sn}$ steel, the frequencies with misorientation angles lower than $20^{\circ}$ decreased during grain growth. On the contrary, the distribution of the $0.1 \mathrm{Sn}$ steel did not change during grain growth. Figure 10 shows the results of another analysis around the $\{411\}<148>$ grains. In contrast to the result for the $\{111\}<112>$ grains showing that the addition of Sn did not affect the behavior of the distribution change of misorientation during grain growth, the frequency between $20^{\circ}$ and $40^{\circ}$ decreased during grain growth in both steels in the analysis of the $\{411\}<148>$ grains.

If it is assumed that the decrease in frequency of a grain boundary with a specified misorientation angle corresponds to faster migration of this grain boundary compared with other grain boundaries, it can be concluded that the addition of $\mathrm{Sn}$ retarded the migration of the grain boundaries around $\{111\}<112>$ grain boundaries but did not affect the migration of the grain boundaries around $\{411\}<148>$ grains.

It is well known that the grain boundary energy is a function of the misorientation angle. ${ }^{17)}$ Also, Omura and Hayakawa $^{18)}$ related the grain boundary energy to the relative mobility of grain boundaries and concluded that the (a)

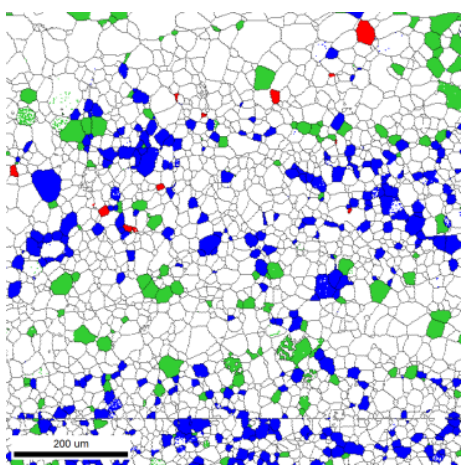

(c)

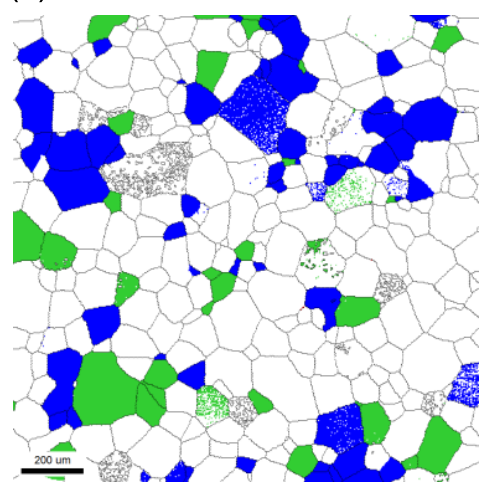

(b)

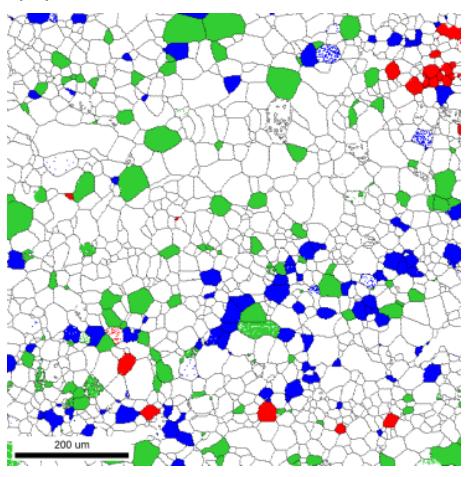

(d)

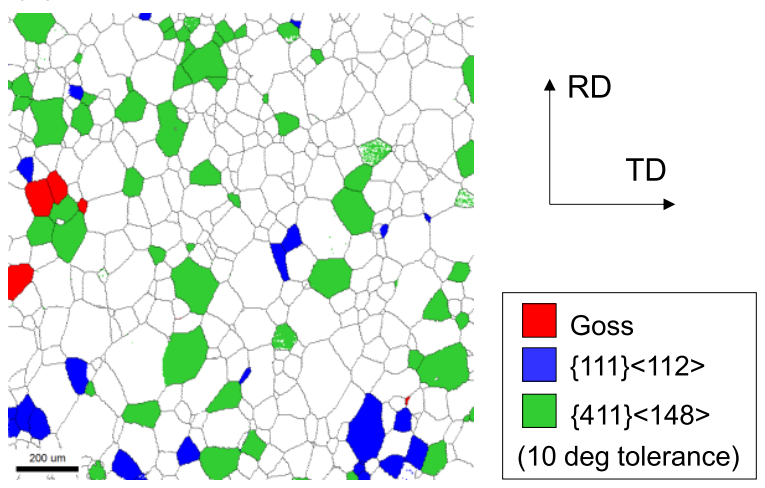

Fig. 7. Grain map of (a), (c) the 0.0Sn steel and (b), (d) the 0.1Sn steel. (a) and (b) were taken as recrystallized and (c) and (d) were taken after the primary recrystallization annealing at $850^{\circ} \mathrm{C} \times 120 \mathrm{~s}$. The Goss, $\{111\}<112>$, $\{411\}<148>$ grains are colored in red, blue and green respectively (tolerance $10^{\circ}$ ). (Online version in color.) 
(a)

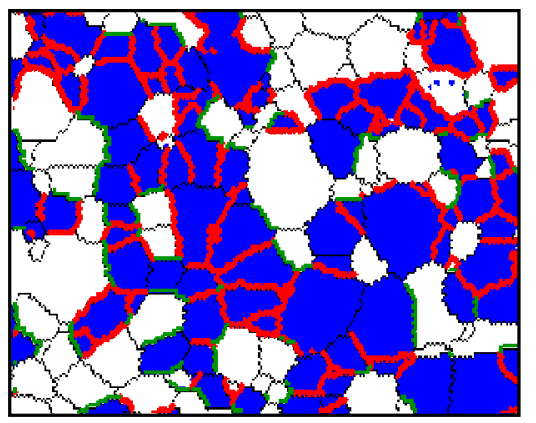

(b)

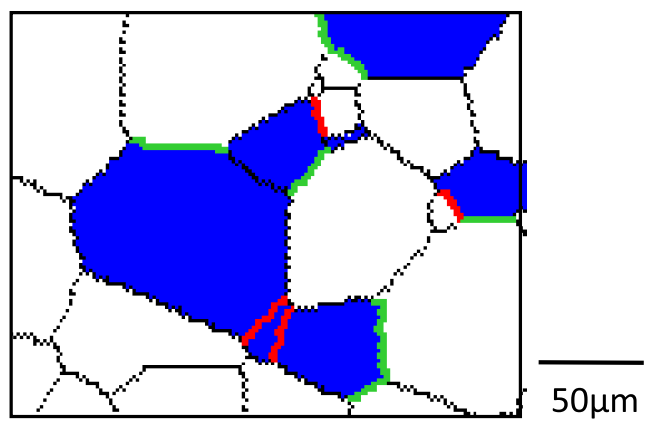

Fig. 8. Grain map of the $0.0 \mathrm{Sn}$ steel (a) as-recrystallized and (b) at $850^{\circ} \mathrm{C} \times 120 \mathrm{~s}$. The $\{111\}<112>$ grains are shown in blue (tolerance $10^{\circ}$ ). Grain boundaries with misorientation angles of less than $20^{\circ}$ are shown in red, and those with misorientation angles of between $20^{\circ}$ and $40^{\circ}$ are shown in green. (Online version in color.)
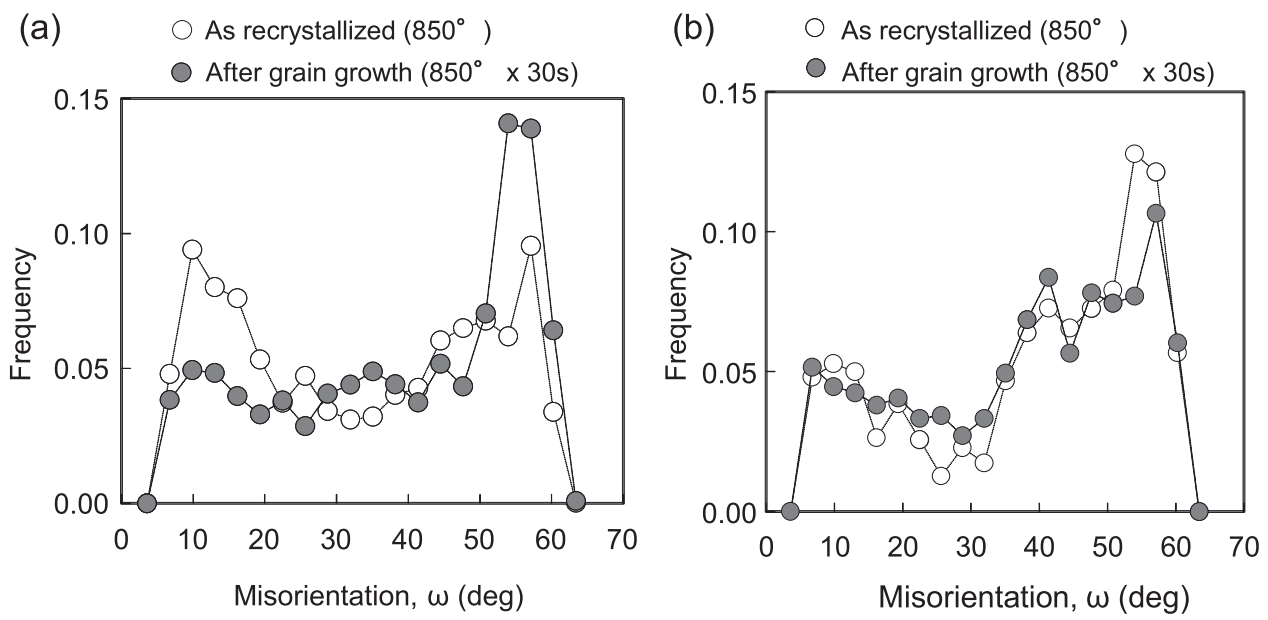

Fig. 9. Grain boundary misorientation distribution around $\{111\}<112>$ grains in as-recrystallized condition and after grain growth for (a) the $0.0 \mathrm{Sn}$ steel and (b) the $0.1 \mathrm{Sn}$ steel.
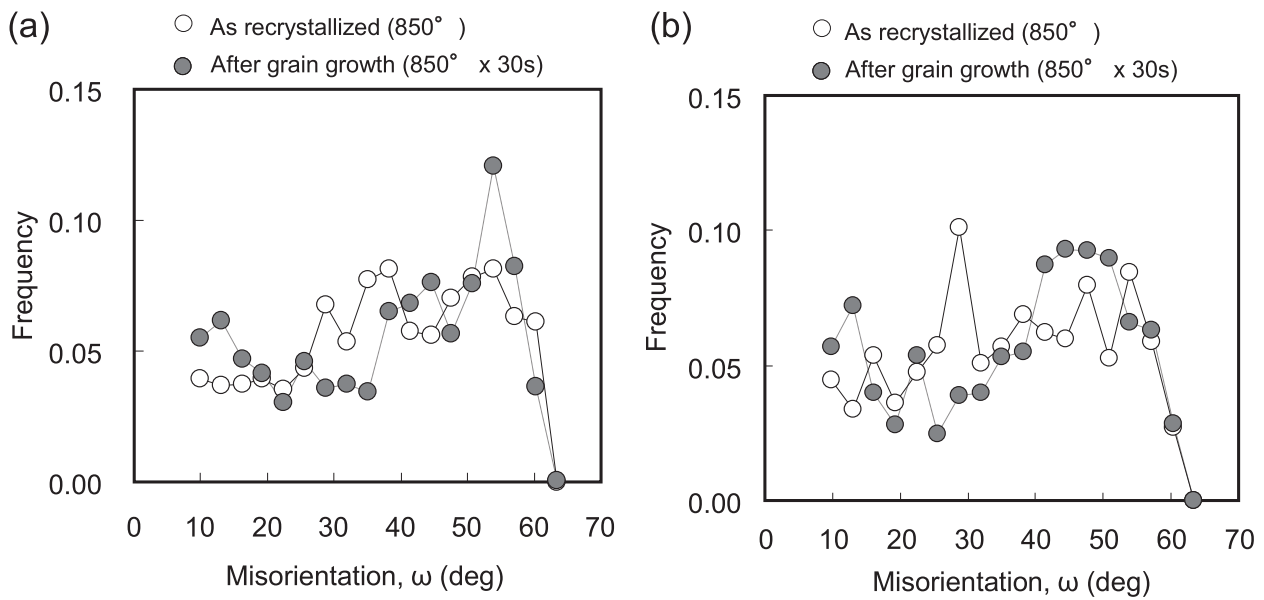

Fig. 10. Grain boundary misorientation distribution around $\{411\}<148>$ grains in as-recrystallized condition and after grain growth for (a) the $0.0 \mathrm{Sn}$ steel and (b) the $0.1 \mathrm{Sn}$ steel.

relative mobility is highest at around $30^{\circ}$ of misorientation angle. Additionally, the grain boundary segregation generally decreases the grain boundary energy. ${ }^{19)}$

Assuming that the addition of Sn preferentially decreases the grain boundary energy at low angle boundaries and high angle boundaries $\left(\omega>45^{\circ}\right)$, the evolution of the $\{411\}<148>$ grains during grain growth in the $0.1 \mathrm{Sn}$ steel would be explained as follows. The $\{111\}<112>$ grains, which orientation is the main component just after the completion of recrystallization in the Sn-less steel, have low and high angle grain boundaries with relatively low mobility compared with the boundaries around the misorientation of $30^{\circ}$. In the Sn-added steel, $\mathrm{Sn}$ atoms segregate preferentially on the low angle boundaries and high angle boundaries $\left(\omega>45^{\circ}\right)$ and decrease the grain boundary energy, resulting in the retardation of grain boundary migration. In contrast, the grain boundaries around $\{411\}<148>$ grains just after the completion of recrystallization have a high frequency 
around the $30^{\circ}$ misorientation. Hence, the decrement of grain boundary energy by $\mathrm{Sn}$ segregation is relatively low, and grain growth migration is not affected.

\subsection{Grain Growth Simulation}

To investigate the mechanism of the change of texture during grain growth by the $\mathrm{Sn}$ addition, a Monte Carlo simulation of normal grain growth was conducted. The Monte Carlo model for normal grain growth was developed by Anderson et al. ${ }^{20)}$ and extended to treat anisotropic grain boundary energies and mobilities. ${ }^{21)}$ In the present study, the model suggested by Hayakawa and Szpunar ${ }^{22)}$ was applied to treat the anisotropic grain boundary energies depending on the grain boundary misorientation angle $\omega$.

The dependence of the grain boundary energy $(E)$ on the misorientation angle is described as follows. ${ }^{18)}$

$$
E(\omega)=\frac{1}{\omega_{m}} \omega(A-\ln \omega)
$$

$\omega_{\mathrm{m}}$ and A are experimentally measured values, ${ }^{18)} 28.2^{\circ}$ and 0.294 , respectively. Grain boundary migration is described by calculating the transition of the crystal orientation at each lattice to another orientation of adjacent grains in each Monte Carlo Step (MCS). The transition probability (W) is given by

$$
\mathrm{W}=\left\{\begin{array}{cc}
M \exp \left(\frac{-\Delta E}{k_{B} T}\right) & \Delta E>0 \\
M & \Delta E \leq 0
\end{array} .\right.
$$

where, $\Delta E, k_{B}$ and $T$ are the change of free energy caused by the orientation transition, Boltzmann constant and temperature, respectively. $M$ is relative grain boundary mobility. Here, it is assumed that $M$ depends on the misorientation angle as follows.

$$
M=\left\{\begin{array}{cc}
X & 0^{\circ} \leq \omega \leq 15^{\circ} \\
1 & 15^{\circ}<\omega<45^{\circ} \\
X & 45^{\circ} \leq \omega
\end{array}\right.
$$

$X$ is an artificial parameter corresponding to the suppression of the migration of low and high angle grain boundaries. In this study, grain boundary mobility is defined as isotropic in Sn-free steels, where $X=1$, and anisotropic in the case of Sn-added steels and $X<1$, as shown in Fig. 11.

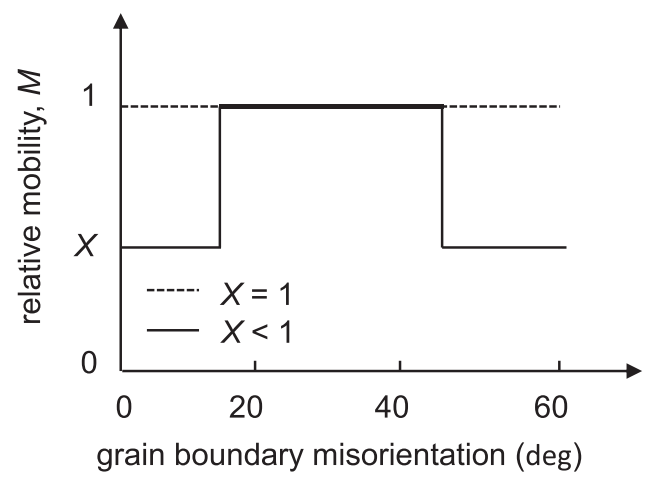

Fig. 11. Schematics of relative grain boundary mobility used for calculation.
In the initial stage of the simulation, 15000 grains were placed in a 3 -dimensional space $(x, y, z)$ with $142 \times 164 \times 174$ lattices by using Volonoi division, as shown in Fig. 12(a). Next, a randomly chosen crystal orientation was assigned to each grain with the same ratio of experimentally measured ODF as the as-recrystallized $0.0 \mathrm{Sn}$ steel. The $\varphi_{2}=45^{\circ}$ sections of the experimentally measured and numerically reconstructed ODFs are shown in Figs. 12(b) and 12(c), respectively. It is noted that the same grain arrangement and orientation distribution as shown in Figs. 12(a) and 12(c) were used as the initial state for all of the following simulations.

Figure 13 shows the average grain diameter ratio $\left(\bar{r} / \bar{r}_{0}\right)$ of the results calculated with $X=1$ and observed in the $0.0 \mathrm{Sn}$ steel annealed at $850^{\circ} \mathrm{C}$. Here, $\bar{r}$ is the average grain diameter and $\bar{r}_{0}$ is the initial average grain diameter at

(a)

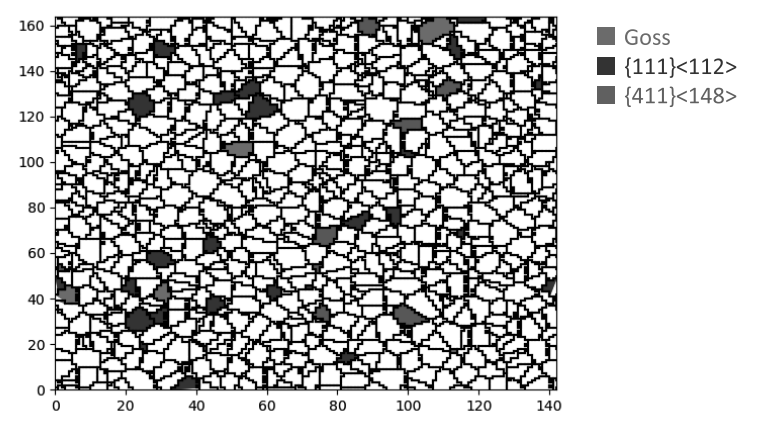

(b)

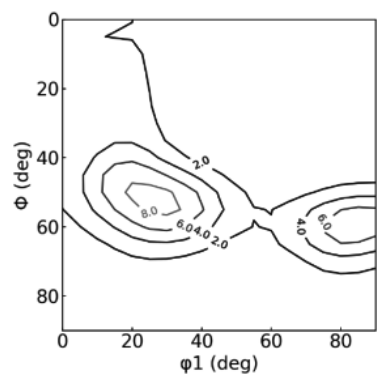

(c)

Fig. 12. (a) $z=0$ section of initial distribution of grains used for grain growth simulation. $\varphi_{2}=45^{\circ}$ sections of ODFs of (a) $0.0 \mathrm{Sn}$ from experiment and (b) reconstructed from (a).

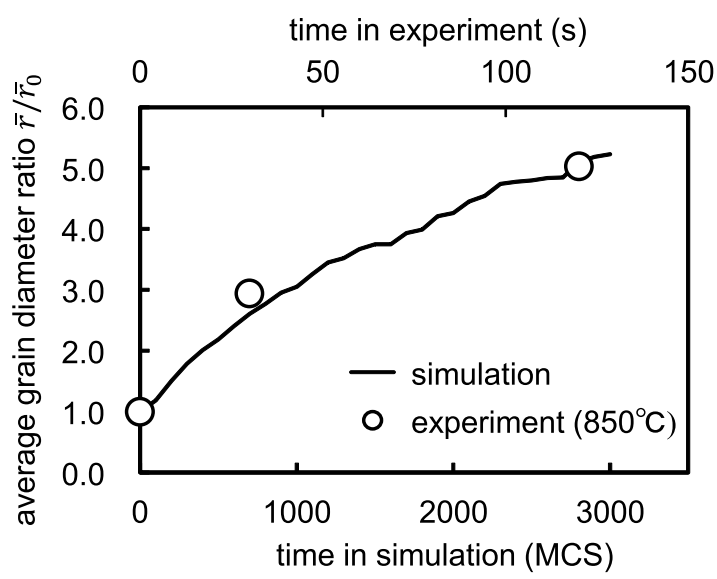

Fig. 13. Average grain diameter ratio during grain growth in Monte Carlo simulation $(X=0)$ and experiment with 0.0 $\mathrm{Sn}$ annealed at $850^{\circ} \mathrm{C}$. 
MCS $=0$ in the simulation and just after the completion of recrystallization in the experiment. The grain growth behavior in the simulation until 3000 MCS was in good agreement with the experimental data. Hence, the microstructure and texture evolution were evaluated appropriately.

With $X=1,\{411\}<148>$ grains were gradually consumed and a strong $\{111\}<112>$ component remained in the texture at $3000 \mathrm{MCS}$, as shown in Fig. 14. The texture at 3000 MCS showed good agreement with the texture of the 0.0Sn steel after grain growth, as shown in Fig. 5(c). However, with $X=0.6,\{411\}<148>$ grains remained without being consumed at $3000 \mathrm{MCS}$, as shown in Fig. 15. Additionally, although the main component of the texture was still $\{111\}<112>$, a subcomponent having the $\{411\}<148>$ orientation appeared at $3000 \mathrm{MCS}$. The change of textures in the simulation corresponds with the experimental result shown in Figs. 5 and 6 . Also, the increase of the fraction of $\{411\}<148>$ grains by reducing $X$ in the simulation corresponds with the results of the experiment as shown in Fig. 7. The average grain diameter ratio of the grains with Goss, $\{111\}<112>$ and $\{411\}<148>$ orientations at $3000 \mathrm{MCS}$ are plotted as a function of the parameter $X$ in Fig. 16, where these three orientations showed different grain growth behavior. The average grain diameter ratio of $\{111\}<112>$ grains showed its maximum at $X=1$ and gradually decreased with decreasing $X$. On the other hand, the average grain diameter ratio of the $\{411\}<148>$ grains was 0 at $X=1$ and reached its maximum at around $X=0.6$. Goss grains kept the ratio of 0 with $X>0.4$ and maximized at around $X=0.2$. These results indicate that reduced mobility of the low and high angle grain boundaries causes the change of texture after

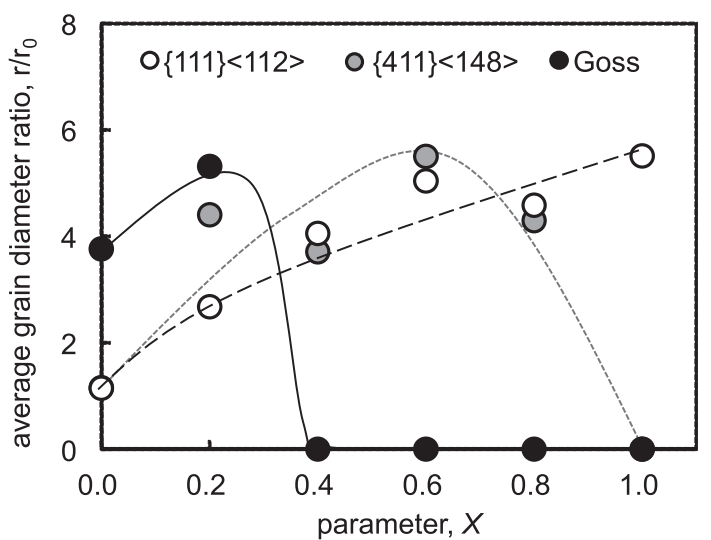

Fig. 16. Average grain diameter ratios of grains with Goss, $\{111\}<112>$ and $\{411\}<148>$ orientations at $3000 \mathrm{MCS}$ with different parameter $X$. (a)

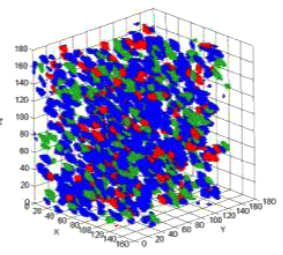

(e)

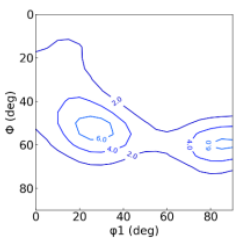

(b)

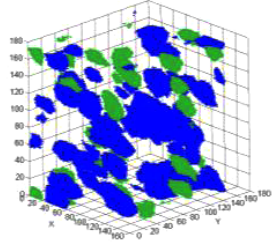

(f)

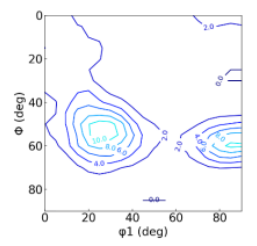

(c)

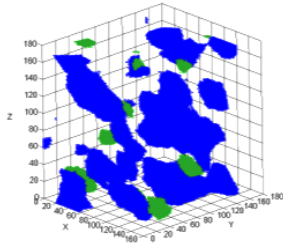

(g)

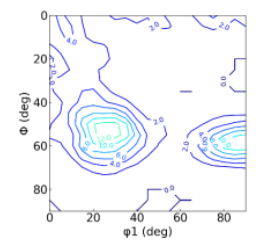

(d)

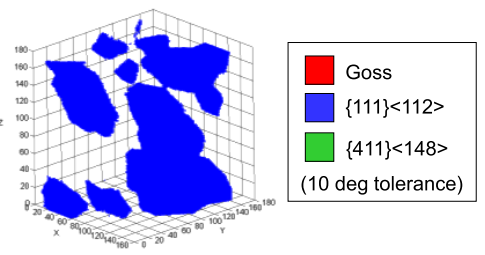

(h)

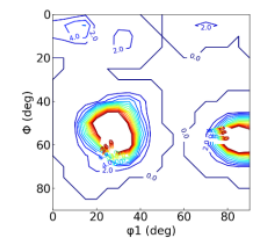

Fig. 14. Grain growth behavior $(X=1.0)$ of grains with Goss, $\{111\}<112>$ and $\{411\}<148>$ orientations (a), (b), (c), (d) and $\varphi_{2}=45^{\circ}$ sections of ODFs (e), (f), (g), (h) during the grain growth simulation at (a), (e) 0 MCS, (b), (f) 500 MCS, (c), (g) 1000 MCS and (d), (h) 3000 MCS. (Online version in color.)

(a)

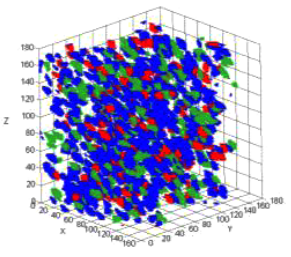

(e)

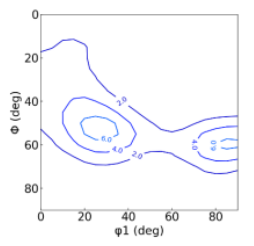

(b)

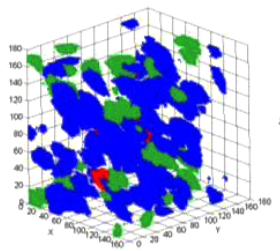

(f)

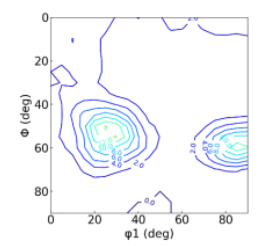

(c)

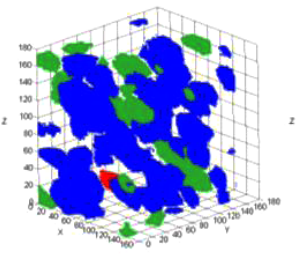

(g)

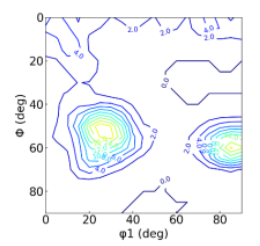

(d)

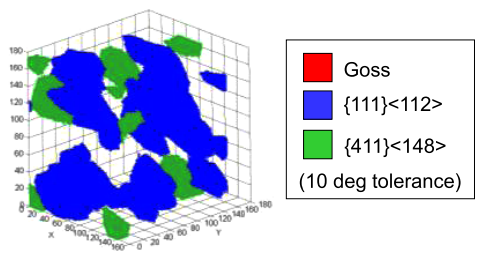

(h)

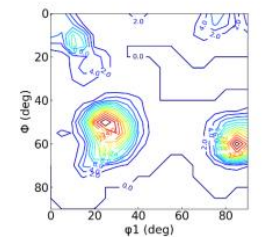

Fig. 15. Grain growth behavior $(X=0.6)$ of grains with Goss, $\{111\}<112>$ and $\{411\}<148>$ orientations (a), (b), (c), (d) and $\varphi_{2}=45^{\circ}$ sections of ODFs (e), (f), (g), (h) during the grain growth simulation at (a), (e) 0 MCS, (b), (f) 500 MCS, (c), (g) 1000 MCS and (d), (h) 3000 MCS. (Online version in color.) 
(a)

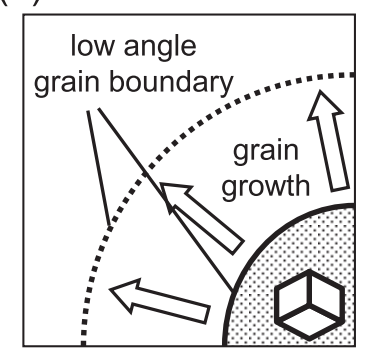

(c)

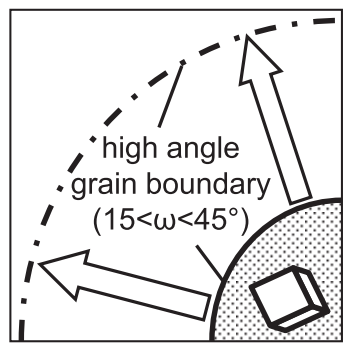

(b)

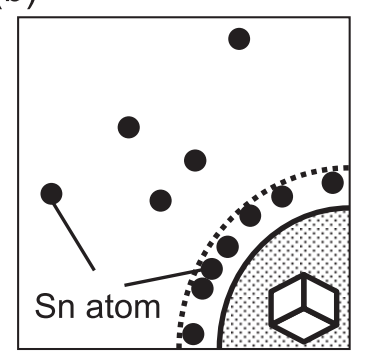

(d)

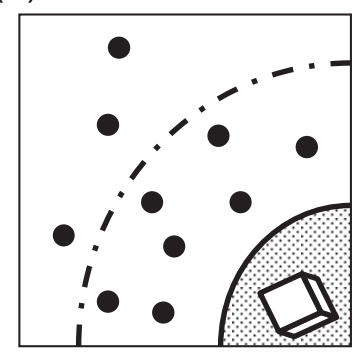

Fig. 17. Schematics of suggested mechanism of preferential texture development of $\{411\}<148>$ orientation during grain growth under the existence of solute Sn atoms. (a), (b) show the grain growth behaviors without solute $\mathrm{Sn}$ atoms and (b), (d) with solute Sn atoms. (a), (b) show the behavior around $\{111\}<112>$ grains and (c), (d) show that around $\{411\}<148>$ grains.

grain growth observed in the present experiments, even if the initial texture was the same.

In High-Energy boundary model, ${ }^{18,22-24)}$ which mainly treats secondary recrystallization of $\mathrm{Si}-\mathrm{Fe}$ alloys, low and high angle grain boundaries are considered to have relatively low mobility compared with grain boundaries having intermediate misorientations. ${ }^{25}$ ) If this model is applied to normal grain growth, it can be thought that the grain boundaries around $\{111\}<112>$ grains just after recrystallization have relatively low mobility because these boundaries mainly consist of low and high angle grain boundaries. On the other hand, the grain boundaries around $\{411\}<148>$ grains just after recrystallization have relatively high mobility because these boundaries are mainly high angle boundaries $\left(15<\omega<45^{\circ}\right)$.

In the presence of solid solute atoms, a moving boundary faces a net force with the opposite direction to the direction of movement ${ }^{26)}$ due to the segregation of the solute atoms. In particular, the low angle boundaries face a strong effect because solute Sn can keep up the movement of low angle boundaries with low mobility. Hence, a strong effect of dragging by the segregation of solute atom would retard the migration of low angle boundaries, and the development of the $\{111\}<112>$ components is suppressed, as shown at Fig. 17(b). On the other hand, since $\{411\}<148>$ grains have a higher frequency of high angle boundaries $\left(15<\omega<45^{\circ}\right)$, which have higher mobility than low angle boundaries, the dragging forces on these boundaries are weak because the solute atoms can no longer keep pace with the movement of high angle boundaries $\left(15<\omega<45^{\circ}\right)$, as shown at Fig. 17(d). This anisotropic dragging effect results in the preferential growth of the $\{411\}<148>$ grains during grain growth in the Sn-added steel.

\section{Conclusions}

The effect of solute $\mathrm{Sn}$ on the evolution of the primary recrystallization texture was examined for 3\% Si steel with and without solute $\mathrm{Sn}$. The following results were obtained:

(1) Without solute $\mathrm{Sn}$, the main texture component just after the completion of recrystallization was the $\{111\}<112>$ orientation, which remained as the main texture component after grain growth at $850^{\circ} \mathrm{C}$.

(2) With solute $\mathrm{Sn}$, the main texture component just after the completion of recrystallization was $\{111\}<112>$. However, the $\{411\}<148>$ orientation replaced $\{111\}<112>$ as the main texture component during grain growth.

(3) The frequency of low angle boundaries around $\{111\}<112>$ grains decreased during grain growth without $\mathrm{Sn}$ addition, but did not change with Sn addition.

(4) The frequency of high angle boundaries with a misorientation angle between $15^{\circ}$ and $45^{\circ}\left(15<\omega<45^{\circ}\right)$ around $\{411\}<148>$ grains decreased during grain growth in both steels.

(5) A Monte-Carlo grain growth simulation suggested that reducing of the mobility of low angle boundaries and high angle boundaries $\left(\omega>45^{\circ}\right)$ enhanced the development of the $\{411\}<148>$ grains during grain growth.

(6) The difference in mobility between the low angle boundaries and high angle boundaries $\left(15<\omega<45^{\circ}\right)$ would cause an anisotropic solute drag effect on the grain boundaries and result in preferential growth of the $\{411\}<148>$ grains.

\section{REFERENCES}

1) H. Toda, M. Kohno, M. Ishida and S. Matsuoka: Materia Jpn., 50 (2011), 33

2) D. Hao, Z. Yu, Y. Xiao-jun and L. Fa-zeng: J. Iron Steel Res., 16 (2009), 86.

3) T. Kubota, K. Kuroki, Y. Matsuo and N. Takahashi: Mater. Sci. Forum, 204-206 (1996), 539.

4) S. Nakajima, K. Takashima, J. Harase, A. Takemasa and K. Takimoto: J. Jpn. Inst. Met. Mater., 55 (1991), 1400.

5) M. Godec, M. Jenko, H. J. Grabke and R. Mast: ISIJ Int., 39 (1999), 742.

6) F. Vodopivec, F. Marinsek, F. Gresovnik, D. Gnidovec, M. Pracek and M. Jenko: J. Magn. Magn. Mater., 97 (1991), 281.

7) M. Takashima, T. Obara and T. Kan: J. Mater. Eng. Perform., 2 (1993), 249.

8) G. Lyudkovsky and P. K. Rastogi: Metall. Trans. A, 15 (1984), 257.

9) H. Shimanaka, T. Irie, K. Matsumura and H. Nakamura: J. Magn. Magn. Mater., 19 (1980), 63.

10) S. Lee and B. C. De Cooman: Mater. Sci. Forum, 654-656 (2010), 302.

11) S. Lee and B. C. De Cooman: ISIJ Int., 52 (2012), 1162.

12) J. T. Park, J. S. Woo and S. K. Chang: J. Magn. Magn. Mater., 182 (1998), 381.

13) C. K. Hou, C. T. Hu and S. Lee: J. Magn. Magn. Mater., 109 (1992), 7.

14) I. Tanaka and H. Yashiki: ISIJ Int., 47 (2007), 1666.

15) K. Pawlik: Phys. Status Solidi B, 134 (1986), 477.

16) X. Wang, B. Zhou, Z. Guo, Y. Liu, J. Wang and X. Su: Calphad, 57 (2017), 88 .

17) C. G. Dunn and F. J. Lionetti: Trans. AIME, 185 (1949), 125.

18) T. Omura and Y. Hayakawa: Mater. Trans., 54 (2013), 14

19) E. D. Hondros and M. P. Seah: Int. Met. Rev., 22 (1977), 262.

20) M. P. Anderson, D. J. Srolovitz, G. S. Grest and P. S. Sahni: Acta Metall., 32 (1984), 783.

21) A. D. Rollett, D. J. Srolovitz and M. P. Anderson: Acta Metall., 37 (1989), 1227.

22) Y. Hayakawa and J. A. Szpunar: Acta Mater., 45 (1997), 4713

23) Y. Hayakawa and J. A. Szpunar: Acta Mater., 45 (1997), 1285

24) Y. Hayakawa, T. Omura and T. Imamura: ISIJ Int., 54 (2014), 2385.

25) D. B. Titorov: Phys. Met. Metallogr., 36 (1973), 82.

26) F. J. Humphreys and M. Hatherly: Recrystallization and Related Annealing Phenomena, 2nd ed., Elsevier, Oxford, (2004), 159. 